\title{
Forum:
}

\section{Reproductive market values explain post-reproductive lifespans in men}

Lucio Vinicius* and Andrea B. Migliano

1211 words

Department of Anthropology, University College London, London, United Kingdom.

14 Taviton Street, WC1H 0BW, London, United Kingdom. Tel: 00442076798649.

*Corresponding author: Vinicius, L. (1.vinicius@ucl.ac.uk)

Keywords: men; ageing; last reproduction; menopause; hunter-gatherers; pastoralists 


\begin{abstract}
Post-reproductive lifespans of men vary across traditional societies. We show that if sexual selection operates on male age-dependent resource availability (or 'reproductive market values'), the result is variation in male late-life reproduction across subsistence systems. This highlights the uniqueness of both male and female reproductive senescence in humans.
\end{abstract}


Women receive almost all the attention in human life history studies due to their long post-reproductive lifespans (PRLS) and menopause. In contrast, the prevailing view is that men reproduce until old age in traditional societies and have short PRLSs. Often described under the stereotype of polygynous or serially monogamous patriarchs [1] and lacking an 'andropause' (mid-life infertility), men have been unsurprisingly neglected in most studies of human reproductive senescence.

However, evidence points against universal male late-life reproduction. Recently a skill-based model predicted the early reproductive termination of both men and women among Tsimane forager-horticulturalists [2]. Data from other traditional populations reveal significant variation in male PRLS (for original sources of male fertility curves, food production and polygyny levels discussed below, see reference in [3]). While men typically reproduce until old age in Gambian farmers and Turkana pastoralists, reproductive cessation differ by only a few years between women and men in the Dobe !Kung (Ju/'hoansi), Hadza and Agta hunter-gatherers. Ache huntergatherers and Tsimane and Yanomamo forager-horticulturalists show intermediate levels of male late-life reproduction. It is therefore surprising that a near consensus over male late-life reproduction in small-scale societies has been established. In addition, the proposal of an invariable male life history seems at odds with the widely documented cross-cultural variation in other aspects of male reproductive strategies such as marriage systems and levels of parental investment.

We therefore argue for an increased effort to investigate the adaptive reasons for variation in male reproductive ageing across traditional populations (Text Box 1). This change in perspective should also bring attention to the need of a significant effort to collect and publish more data on male reproduction. Male reproductive 
curves are only available for a few traditional populations (!Kung, Hadza, Agta and Ache hunter-gatherers, Tsimane and Yanomamo forager-horticulturalists, Turkana pastoralists and Gambian farmers). No curves are known for polygynous Australian hunter-gatherers or polyandrous South-American foragers. Historical populations such Christian Finns [4] have featured in analyses of male reproductive senescence, but they have often outlawed polygamy and divorce thus creating constraints on male late-life reproduction not found in traditional populations.

Here we propose that 'reproductive market values', which reflect the agedependence of individual desirability as reproductive partners, can explain variation in male PRLS across traditional populations. The reason is that reproductive market values should respond differently to age in men and women. Whereas in women they should drop to zero at the age of menopause, reproductive market values of older men reflect their available resources in late life. We therefore postulate that male late-life reproduction must vary with subsistence system (Text Box 1). In simple huntergatherers, male food production is limited by physical condition and declines in late life, explaining early reproductive cessation among !Kung, Hadza and Agta men. In contrast, among pastoralists and farmers male wealth often increases with age, accounting for late-life reproduction in male Turkana and rural Gambians. Finally, variable levels of horticulture among forager-horticulturalists create some opportunities for land and resource control by older men, explaining intermediate levels of male late-life reproduction in the Tsimane and Yanomamo. Reproductive market values are an extension of the theory of 'biological markets' [5] and the result of sexual selection on an age-dependent male trait, namely available resources that women desire to convert into investment in offspring. As such, they draw attention to 
a unique male life history trait: the dependence of male PRLS duration on populationspecific opportunities of resource control at old age.

Our proposal concurs with previous accounts of marriage systems as responses to ecology and subsistence mode [6, 7]. Due to underlying effects of socioecology, we argue that correlations between male late-life reproduction and marriage system are expected. For example, in extant hunter-gatherers food production decreases with age and as result older men are unlikely to attract additional fertile wives, explaining both reduced male late-life reproduction and low polygyny rates (under 10\%) in the !Kung, Hadza, and Agta. In farming and pastoralist societies where wealth can increase with age [8], older men are able to remain above polygyny thresholds, explaining both extended male reproduction and high polygyny in rural Gambians (40\%) and Turkana (80\%). The argument can be extended to exceptional marriage systems, including the high polygyny of past Tiwi hunter-gatherers from Australia, where older males were able to co-opt female work by exchanging daughters with male allies, avoiding decline in their reproductive market values at old age [9]. Another extreme example is the coexistence of polyandry, monogamy and polygyny in South-American foragerhorticulturalists such as the Zo'e [10]. In this group, low-producing men might be forced to share a wife and accept shared paternity of her children. Among the Zo'e', we predict that the heads of polyandrous household (the main husband) should be able to extended reproduction into late-life, but paternity will be shared with additional husbands. Although our interpretations of the Tiwi and Zo'e are consistent with published ethnographies, data on male reproduction and resource availability in those are required for testing.

This leads to the question of how variation in male reproductive senescence and marriage systems evolved. Ancestral hunter-gatherer men could have stopped 
reproduction early (as !Kung and Hadza do) or late (as the Tiwi did). Polygyny has been traditionally seen as ancestral in humans, but some recent studies have favoured monogamy and pair bonding [11]. Alternatively, male reproductive senescence and mating systems could have varied in ancestral humans. This view is consistent with growing evidence that the genus Homo has always been characterised by adaptability to environments ranging from harsh to highly productive [12].

Reproductive market values can also explain the combination of male long PRLS in some populations and absence of male mid-life infertility. Due to the high and unavoidable costs of human offspring, women are not expected to increase direct fitness by extending reproduction into late life, and therefore their extended lifespans and long PRLS are often seen as adaptations increasing indirect fitness through grandmothering effects [4]. In contrast, extended male lifespans can be driven by direct fitness gains through continued reproduction. However, older men often fail to reproduce due to low resource availability. As a result, maladaptive and purely plastic long PRLS occur in groups such as!Kung, Hadza, Agta hunter-gatherers. In the past, those groups could have coexisted with others where male late-life reproduction was frequent (as in the Tiwi). Genes preserving extended longevity and late-life fertility could therefore be spread from late-life reproducing individuals. Agent-based simulation could test whether variable late-life reproduction is enough to explain variable male PRLS and the absence of andropause (Test Box 2).

Testing the many predictions from the reproductive market value approach faces various limitations imposed by the absence of data. Therefore increased effort should be directed towards collection and publication of age-specific data on male reproduction and resource control especially at old age. Nonetheless, existing evidence convincingly indicates that reproductive ageing is more complex and 
variable in men than in other male primates. Models of human senescence have traditionally focused on one sex only, attributing extended longevity and long PRLS either to grandmothers or patriarchs. Recognising that male reproductive senescence is variable and adaptive could promote a more balanced view of human life history evolution. We hope this forum inspires a change in attitude towards male life histories and further research into variation in male reproductive senescence across traditional societies.

Acknowledgements. We thank R. Mace and M. Burgerhoff Mulder for insightful comments. ABM is funded by the Leverhulme Trust (grant RP2011-R-045).

\section{References}

[1] Tuljapurkar, S. D. et al. (2007) Why Men Matter: Mating Patterns Drive Evolution of Human Lifespan. PLoS ONE 2: e785.

[2] Kaplan, H. S. et al. (2010) Learning, menopause, and the human adaptive complex. Ann. N. Y. Acad. Sci. 1204, 30-42.

[3] Vinicius, L. et al. (2014) Variation in male reproductive longevity across traditional societies. PLoS ONE 9, e112236.

[4] Lahdenpera, M. et al. (2011) Selection on male longevity in a monogamous human population: late-life survival brings no additional grandchildren. J. Evol. Biol. 24, 1053-1063.

[5] Noë, R. et al. (1991) The market effect: An explanation for payoff asymmetries among collaborating animals. Ethology 87, 97-118. 
[6] Flinn, M. V. and Low, B. S. (1986) Resource Distribution, Social Competition, and Mating Patterns in Human Societies. In Ecological Aspects of Human Social Systems (Rubinstein, D. and Wrangham, R. eds.), pp. 227-243, Princeton Univ. Press. [7] Kaplan, H.S et al. (2008) The evolutionary and ecological roots of human social organization. Phil. Trans. R. Soc. B 364, 3289-3299.

[8] Kaimba, G.K. et al. (2011) Effects of cattle rustling and household characteristics on migration decisions and herd size amongst pastoralists in Baringo District, Kenya. Pastoralism 1, 18.

[9] Hart, C.W.M. and Pilling, A.R. (1960) The Tiwi of North Australia. Holt and Co., New York.

[10] Cartagenes, R. (2010). Ensaio Sobre os Zoe. Retrieved from http://www.amazoe.org.br/textoreferencia/ensaio_livro_tupi.pdf [11] Chapais, B. (2013) Monogamy, strongly bonded groups, and the evolution of human social structure. Evol. Anthropol. 22, 52-65.

[12] Anton, S.C. et al. (2014) Evolution of early Homo: An integrated biological perspective. Science 345, 1236828. 
A) Hunter-gatherers
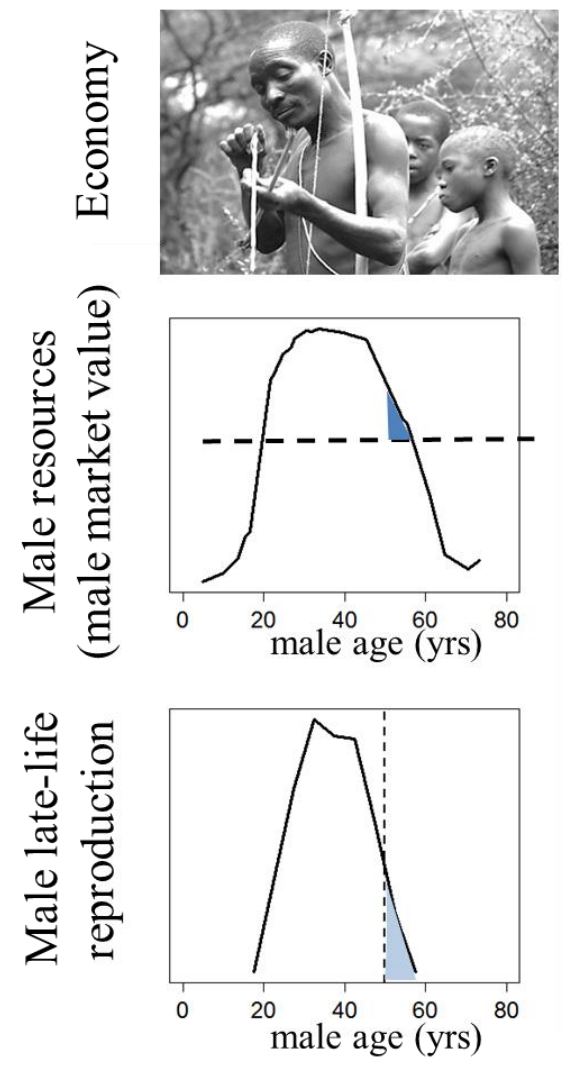

B) Forager-horticulturalists
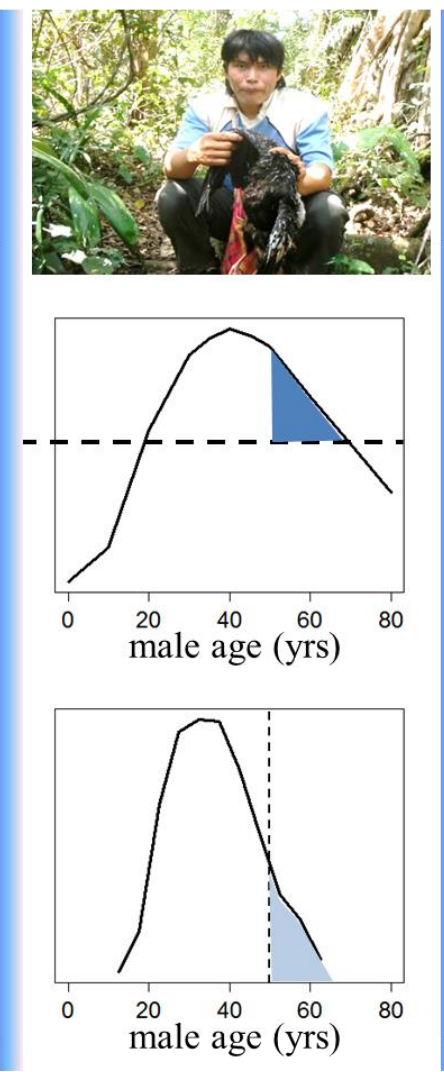

C) Pastoralists
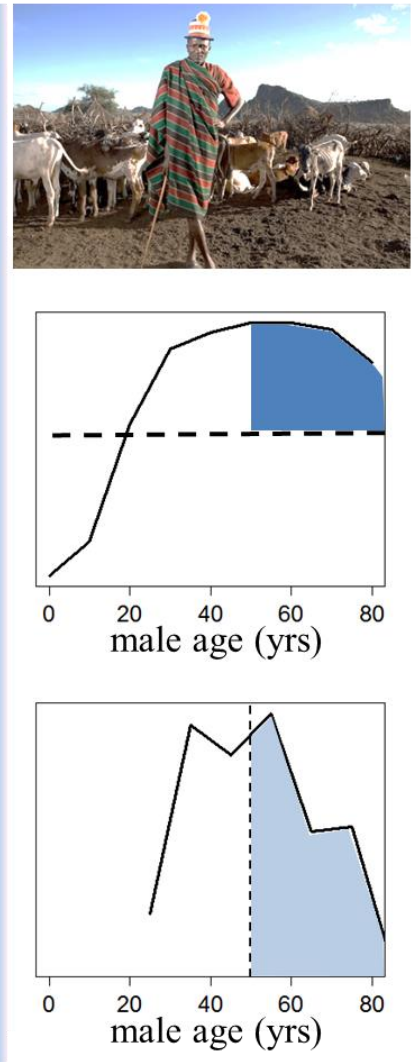

Test Box 1. Economy, male reproductive market values and male late-life

reproduction. Male late-life reproduction depends on resource availability at old age.

A) In hunter-gatherers such as the Hadza, food production remains above a 'marriage threshold' (a theoretical level of male resources that fertile women require from a potential husband; horizontal hashed line) for most of adult life (middle panel). However, male production often falls below the marriage threshold at old age (here defined as the age of menopause; vertical hashed line). Male fertility is only slightly extended relative to women's (light blue area, bottom panel). B) In foragerhorticulturalists such as the Tsimane, older men can maintain food production at higher levels than hunter-gatherers due to horticulture, leading to extended late-life reproduction compared to Hadza. C) In pastoralists such as the Turkana, male 
accumulated wealth (herd size) often remains high or even increases at old age, and men are often able extend reproduction into their 70s. All fertility and production curves were taken from sources listed in reference [1]. No wealth-by-age curve is known for pastoralists, and we present a hypothetical curve based on studies suggesting an increase in male wealth with age [8]. 
Text Box 2. Outstanding questions. Below we list predictions, summary of current evidence, and shortcomings of the reproductive market value approach, together with suggestions for future work.

\begin{tabular}{|c|c|c|}
\hline Predictions & Current evidence & Shortcomings and future steps \\
\hline $\begin{array}{l}\text { - Male PRLS varies across } \\
\text { subsistence systems }\end{array}$ & $\begin{array}{l}\text { - Data from eight traditional } \\
\text { populations show long PRLS } \\
\text { in hunter-gatherers, short in } \\
\text { agro-pastoralists, intermediate } \\
\text { in forager-horticulturalists }\end{array}$ & $\begin{array}{l}\text { - Male fertility curves needed } \\
\text { from other traditional } \\
\text { populations, especially } \\
\text { Australian hunter-gatherers, } \\
\text { pastoralists and small-scale } \\
\text { farmers }\end{array}$ \\
\hline $\begin{array}{l}\text { - Resource availability at old } \\
\text { age determines male late-life } \\
\text { reproduction }\end{array}$ & $\begin{array}{l}\text {-In male hunter-gatherers, food } \\
\text { production curves decline at } \\
\text { old age } \\
\text { - Accumulated wealth increases } \\
\text { with male age in pastoralists } \\
\text { and farmers }\end{array}$ & $\begin{array}{l}\text { - Age-dependent data on male } \\
\text { resources (herd sizes, land } \\
\text { owned, fraction of } \\
\text { horticulture) are needed }\end{array}$ \\
\hline $\begin{array}{l}\text { - Male PRLS varies with } \\
\text { marriage system }\end{array}$ & $\begin{array}{l}\text { - Low polygyny and long male } \\
\text { PRLS in hunter-gatherers } \\
\text { - High polygyny and short } \\
\text { PRLS in Turkana pastoralists } \\
\text { and rural Gambians }\end{array}$ & $\begin{array}{l}\text { - Male fertility curves needed } \\
\text { from polyandrous South } \\
\text { American forager- } \\
\text { horticulturalists, polygynous } \\
\text { Australian hunter-gatherers }\end{array}$ \\
\hline $\begin{array}{l}\text { - Male PRLS and mating } \\
\text { systems varied in ancestral } \\
\text { hunter-gatherers }\end{array}$ & $\begin{array}{l}\text { - Geo-archaeological evidence } \\
\text { indicates ecological variability } \\
\text { in past human environments }\end{array}$ & $\begin{array}{l}\text { - Agent-based simulations of } \\
\text { marriage systems and male } \\
\text { reproductive senescence under } \\
\text { variable ecological conditions }\end{array}$ \\
\hline $\begin{array}{l}\text { - Andropause has not evolved } \\
\text { due to variation in male PRLS }\end{array}$ & $\begin{array}{l}\text { - No evidence of male mid-life } \\
\text { infertility in traditional } \\
\text { populations }\end{array}$ & $\begin{array}{l}\text { - Analyses of male reproductive } \\
\text { success as a function of age at } \\
\text { last reproduction across } \\
\text { traditional societies } \\
\text { - Agent-based simulations of } \\
\text { male PRLS under variable } \\
\text { ecological conditions }\end{array}$ \\
\hline
\end{tabular}

